Article

\title{
Impact of the Interactive Learning Environments in Children's Prosocial Behavior
}

\author{
Lourdes Villardón-Gallego ${ }^{(1)}$, Rocío García-Carrión * (i), Lara Yáñez-Marquina and Ana Estévez \\ Faculty of Psychology and Education, University of Deusto, 48007 Bilbo, Spain; \\ lourdes.villardon@deusto.es (L.V.-G.); lara.yannez@deusto.es (L.Y.-M.); aestevez@deusto.es (A.E.) \\ * Correspondence: rocio.garcia@deusto.es; Tel.: +34-94-413-9160
}

Received: 4 June 2018; Accepted: 19 June 2018; Published: 22 June 2018

\begin{abstract}
Prosocial behavior consists of a set of behaviors that are beneficial to others in the form of sharing and helping. It includes aspects such as solidarity and friendship, and it fosters development and positive psychological functioning; it also improves classroom and school climate. Interactive learning environments may play a crucial role in creating affordances for students to develop prosocial behavior. This study analyzes the impact of two educational interventions based on egalitarian dialogue (Dialogic Literary Gathering and Interactive Groups) on prosocial behavior among fourth grade elementary students. A quasi-experimental design has been carried out, in which measurements have been taken before and after the intervention. Results show that students involved in the Dialogic Literary Gatherings increased significantly their level of prosocial behavior more than those in the control groups. However, no significant differences have been found between students in the experimental and control condition, when considering Interactive Groups. These results have important educational implications for creating conducive learning environments for the development of prosocial behavior.
\end{abstract}

Keywords: prosocial behavior; interactive learning environments; egalitarian dialogue; elementary education

\section{Introduction}

The study of prosocial behavior has emerged as a crucial issue across many diverse disciplines in social and behavioral sciences to advance towards an inclusive and sustainable society [1]. Developing inclusive, innovative and reflective societies is at the heart of the current European agenda for a sustainable development [2]. In this context, education plays a key role to advance towards this goal because its potential to reduce inequalities and social exclusion [2]. Therefore, creating effective learning environments that provide students with academic skills and social competences for their success and inclusion, may contribute to the Sustainable Development Goal 4 "ensure inclusive and quality education for all and promote lifelong learning" [3]. Since prosocial behaviour has been positively related to both academic performance and social skills [4], it seems considerably important to foster its development. Along these lines, schools can be an optimal context for implementing effective interventions that support positive relationships and interactions to ultimately provide students' social, academic and emotional development. Therefore, gathering scientific evidence on which interactive learning environments are effective to foster prosocial behavior, might be a relevant contribution for advancing towards inclusive and sustainable societies [1]. This paper aims at analyzing the efficacy of two particular interactive learning interventions, namely Dialogic Literary Gatherings and Interactive Groups, to improve prosocial development among elementary students. 


\subsection{Prosocial Behavior: A Theoretical Account}

Prosocial behavior is a general term that refers to a set of behaviors including solidarity, cooperation, and helping other people [4]. Also, it encompasses actions such as sharing, consoling, comforting, guiding, rescuing, and defending [4]. Through voluntary actions intended to benefit others [5] it fosters harmony in interpersonal relationships [6,7]. It is also strongly linked to friendship and to the global prosocial behavior towards friends [8].

Prosocial demeanors may provide a foundation for learning and achievement, as the basic skills to engage and benefit from classroom instructions are provided by the peer-induced effects on prosocial and socially competent behavior [9]. It has long been known that prosocial behaviors affect the well-being of the helper as well as that of the recipient of the help [10].

Longitudinal studies have shown that prosocial behaviors in early childhood predicted academic achievement five years later [11]. Linked to this, prosocial behavior is also positively associated with empathy [12] and it is a critical skill that enables children to function adaptively in a social context and is a negative predictor of aggression [13], bullying [14], and behavior disorder in childhood as well as antisocial behavior in adolescence and adulthood [15].

It is important to understand prosocial actions within the school context. Schools provide children with ongoing opportunities to develop prosocial skills through interactions with peers and teachers in the classroom and, as it has been shown, they can also be an important source of support in students' development of academic skills [4]. However, among the vast majority of the studies conducted in elementary education, the effect of specific socialization processes in prosocial behavior, including the qualities and types of interactions, has been underexamined. Nevertheless, the potential of the interactions has been pointed out in a study that confirmed interaction-based interventions are effective to foster the development of prosocial behaviors in children ages 7 to 8 [16]. Along these lines, the work of Schonert-Reichl and $\mathrm{O}^{\prime}$ Brien indicated that it is possible to promote prosocial behavior by creating a prosocial classroom environment that emphasizes caring for others, mutual respect and cooperation.

\subsection{Dialogic-Based Interventions Towards Prosocial Environments}

Interactive learning environments may play a crucial role in creating affordances that will allow students to engage in positive social interactions and in productive dialogues that foster learning and development. However, some modes of dialogic organization prove to be more beneficial than others [17]. There is a wide array of research exploring the benefits of dialogic teaching and learning and its conduciveness to a more productive academic learning [18]. Most of the studies have focused on how the use of a dialogic teaching approach challenges children's thinking and learning in classrooms based on dialogic interactions [19]. These dialogic features of teaching and learning have also been highlighted as the basis of the inclusive classroom pedagogy [20] and the socially inclusive pedagogy [21].

Some forms of dialogic-based teaching and learning have been shown to improve students' academic achievement and social cohesion, creating an inclusive climate in marginalized communities [22-24]. These studies provided evidence of positive results in academic achievement and social cohesion when implementing two forms of dialogic-based instruction in small mixed-achievement groups and in whole class settings; these two forms of dialogic-based instruction are known as Interactive Groups (IG) and Dialogic Literacy Gathering (DLG). However, no research has been conducted to explore in depth the affordances of these actions for fostering prosocial behavior.

Interactive Groups (IG) is a type of small-group classroom organization in which students solve curricular tasks while supported by a non-teacher adult. In IG, the children, distributed in small mixed-achievement groups, are prompted to help and support each other by a volunteer who interacts with them; possible volunteers include parents, grandparents, community members, or teaching assistants, among others. European research focusing on vulnerable children showed the potential of this intervention for fostering family engagement [25], improving mathematical competence [26], and preventing early segregation [27]. Interactive Groups have been shown to increase opportunities 
for students to engage in learning interactions with diverse peers and adults [28]; however, there is a lack of research on the potential of this intervention to help children develop prosocial skills.

Dialogic Literary Gatherings (DLG), for their part, take place in a whole-class setting where students sit in a circle and engage in meaningful interactions based on a previous reading of great literary works in age-appropriate editions. Students extract meaning of the text: they choose a piece, read it aloud and justify their choice. Other children may agree or disagree, providing justifications and explanations; the teacher's role is to ensure the fair distribution of participation [29]. Students provide intricate explanations and formulate questions that elicit high level thinking and reasoning [29]. In DLGs, students frequently relate the text to their own lives, thus sharing their personal views, feelings and emotions; this has been implemented, for example, in contexts of vulnerability such as that of children living in institutional care or prisons in Spain $[23,30]$. While these features may lead to higher order interactions, no research has explored the extent to which these positive interactions in classroom may help develop prosocial behavior.

Therefore, the objective of this study is to analyze the impact of these two dialogue-based educational actions in the development of students' prosocial behavior. Our hypothesis is that the two types of classroom interventions provide students with opportunities to develop prosocial skills through dialogic interactions. On the one hand, theoretical underpinnings and the ground rules for dialogue that are established during Interactive Groups and Dialogic Literary Gatherings are essential to fostering solidarity relationships through egalitarian participation in the dialogue [31]. The different contributions are taken into consideration according to the validity of their reasoning, instead of being judged on the position of power held by those who make the contributions. On the other hand, fostering an egalitarian participation allows children to become more sociable towards others and, eventually, friendship relationships may emerge [32].

\section{Materials and Methods}

A quasi-experimental study was conducted in a total of 8 Spanish schools, selected through the cluster sampling method. Within each of those schools, two student groups from fourth grade were considered for the study: one experimental group, which received the intervention, and one control group, which continued receiving conventional lessons. The only exception was one school with a larger number of enrolled students, in which two experimental groups and one control group were considered for the study. As for the type of intervention, DLG was implemented in the experimental groups in 4 schools, whereas IG was implemented in the experimental groups in the remaining participating schools.

To assess the impact of interventions, pre-post testing was carried out for the students in the experimental and control groups.

\subsection{Participants}

The research sample consisted of 442 students in the fourth year of Primary Education, with ages ranging from 8 to 11; 239 were boys and 203 were girls. Regarding the type of intervention, 228 children participated in the DLG sessions, with 100 peers serving as the control group; and 214 children engaged in IG, with 97 peers serving as the corresponding control subsample. Table 1 summarizes the sample's distribution.

Table 1. Distribution of the research sample.

\begin{tabular}{ccccc}
\hline School & Intervention & Type of Group & Females $(\boldsymbol{n})$ & Males $(\boldsymbol{n})$ \\
\hline 1 & DLG & Control & & 13 \\
\multirow{2}{*}{2} & \multirow{2}{*}{ DLG } & Experimental & 11 & 12 \\
& & Control & 12 & 12 \\
& & Experimental & 12 & 13 \\
\hline
\end{tabular}


Table 1. Cont.

\begin{tabular}{|c|c|c|c|c|}
\hline School & Intervention & Type of Group & Females $(n)$ & Males (n) \\
\hline \multirow[t]{2}{*}{3} & DLG & Control & 14 & 13 \\
\hline & & Experimental & 15 & 12 \\
\hline \multirow[t]{2}{*}{4} & IG & Control & 12 & 12 \\
\hline & & Experimental & 21 & 26 \\
\hline \multirow[t]{2}{*}{5} & IG & Control & 10 & 17 \\
\hline & & Experimental & 15 & 11 \\
\hline \multirow[t]{2}{*}{6} & IG & Control & 9 & 12 \\
\hline & & Experimental & 11 & 10 \\
\hline \multirow[t]{2}{*}{7} & DLG & Control & 10 & 15 \\
\hline & & Experimental & 21 & 32 \\
\hline \multirow[t]{2}{*}{8} & IG & Control & 9 & 16 \\
\hline & & Experimental & 10 & 13 \\
\hline
\end{tabular}

Note. DLG = Dialogic Literary Gathering, IG = Interactive Group.

\subsection{Instrument}

Prosocial behavior was assessed through Prosocial Behavior Scale, which had already shown satisfactory psychometric characteristics in its Italian and English-language versions in studies with samples of children 7 to 10 years old $[33,34]$.

The original version of the Prosocial Behavior Scale was a 15-item scale (answer format: often = 3; sometimes $=2$; never $=1$ ) including five control items that were eliminated in this study. The contents of the remaining 10 statements focus on children's behavior denoting altruism (e.g., I let others use my toys), trust (e.g., I trust others), and agreeableness (e.g., I try to make sad people happier). The results of the principal component analysis were mostly satisfactory, and the Cronbach's alpha coefficient $(\alpha=0.86)$ confirmed the internal consistency of the scale. Overall, the extracted components accounted for $33.5 \%$ of the total variance [33].

As part of this study, the scale was translated and adapted for its use in the Spanish context. Its psychometric properties and structural testing are detailed later in this study.

\subsection{Procedure}

Once written permission was granted by the principals from the selected schools, both teachers and families were contacted and informed of the nature of the research, stressing that children's participation was anonymous and voluntary. Likewise, it was explained that collected data would be treated with confidentiality and used solely for research purposes. Informed consent forms were distributed to all the parents participating in the study and were then collected through the school. Ethical requirements were addressed following the Ethics Review Procedure established by the European Commission for EU research [35].

Data were collected at two separate time points: before exposing experimental groups to the intervention under research (henceforth, T1) and just after having finished the 10-session intervention period (henceforth, T2). Before starting the research, teachers and volunteers involved received one training session to get acquainted with the intervention in which they would be taking part. Teacher training was delivered by one senior researcher with extensive experience and knowledge in both types of intervention, together with one early career researcher. The sessions took place in the schools.

\subsection{Interventions}

DLG: The experimental groups participated in 10 weekly sessions distributed throughout a school semester. Teachers and children in each school chose a different book to be read and discussed: Homer's Odyssey, The Life of Lazarillo de Tormes, Platero and I, Robin Hood, and Robinson Crusoe. The books were read in age-appropriate versions, adapted for 9-10 years old children. 
IG: The experimental groups took participated in 10 sessions distributed throughout a school semester. The subject was Mathematics and they worked on the curricular tasks planned by the teacher. In each session, teachers proposed an average of 3 to 4 mathematics-related activities to be solved in small heterogeneous groups composed by 4 to 5 pupils. Each task was designed to be solved in 15 to $20 \mathrm{~min}$. When the allotted time elapsed, the teams started working on the next problem. Thus, by the end of the session, every student had worked on all the tasks planned by teacher.

Control groups: In these groups, teachers continue teaching conventional lessons.

\subsection{Analysis}

Data inspections were conducted for the accuracy of data entry, the percentage of missing data, and the assumptions of both univariate and multivariate normality. Given the low missing data rate $(3.24 \%)$, which was considered reasonable [36], the maximum likelihood (ML) estimation method was used together with listwise deletion [37].

Next, the normality assumption was examined in two phases. First, the univariate normality was tested through skewness and kurtosis, assuming that values above 2.3 indicate a large divergence from the normal distribution [38]. Second, multivariate normality was tested via Mardia's standardized estimator, setting a maximum value of 3.00 as the desirable cut-off [39]. Due to the multivariate non-normality of data in the current study, the parameters of the Confirmatory Factor Analysis (CFA) were estimated using the Satorra-Bentler robust corrections. Items were forced to load on their hypothesized factors. The variances for the first observed indicator of each latent variable were fixed to 1 , and the variances for all error weights and the remaining parameters were freely estimated [40].

Then, based on theoretical considerations, two a priori models for assessing prosocial behavior were subjected to CFA. The first one was a unidimensional model (hereafter, M1) in which all items were indicators of a single factor; the second one, in turn, was a second-order factor (hereafter, M2) on which both Solidarity and Friendship Factors loaded on a second-order factor referring to general prosocial behavior. Several fit indices and desirable cut-offs were used to judge the adequacy of the CFA [41]: (a) the S- $\mathrm{B}_{\chi}{ }^{2} / d f$ statistics should be lower than 2.0 [39]; (b) the Root Mean Squared Error of Approximation (RMSEA), with a relative $90 \%$ confidence interval, should be lower than 0.06 [42]; (c) the Goodness of Fit Index (GFI) should be greater than 0.95 [43]; and (d) the Comparative Fit Index (CFI) should be greater than 0.95 [43]. In addition, the Akaike's Information Criterion (AIC) was used to compare the factor structures with different estimated parameters in such a way that lower values would indicate a higher parsimony for the model.

Internal consistency was assessed via the Composite Reliability (CR) and Cronbach's coefficient $(\alpha)$. To interpret the scores, values above 0.50 were considered adequate for the former [44] and values above 0.70 were considered acceptable for the latter [45].

Finally, in order to better gauge the effect of the intervention (Dialogic Literary Gatherings and Interactive Groups) on students' prosocial behavior, a two-way repeated measures ANOVA was conducted with time (T1/T2) as the within-subjects factor, and the type of group (control/experimental) as the between-subjects factors.

\section{Results}

\subsection{Confirmatory Factor Analysis}

The descriptive statistical analysis showed that most items met the criteria set for skewness and kurtosis scores. The only exception was item number 2, with a kurtosis value of 3.20. However, visual inspection of the corresponding graphic distribution showed that, although initially identified as an outlier, it was suitable for retention and inclusion in subsequent analyses. Regarding multivariate normality, the Mardia's standardized estimator was $12.60(p<0.001)$, which encouraged performing the estimations of the CFA using robust methods for standard errors, statistical errors and goodness-of-fit indices. 
With these considerations, the goodness-of-fit indices of the two a priori models were estimated and shown in Table 2. As can be seen, both M1 and M2 showed good fit to data, according to the aforementioned cut-off criteria. However, although the single factor model showed overall adequate goodness-of-fit indices, both the S- $\mathrm{B}_{\chi}{ }^{2} / d f$ ratio and the RMSEA were out of the range of desirable values. The second-order structure, which attempts to better ascertain the structure for prosocial behavior by suggesting two underlying components, was a significantly better fit to data when compared to the unidimensional model $\left(\Delta \mathrm{S}-\mathrm{B}_{\chi}{ }^{2}=57.21, \Delta d f=2, p<0.001\right)$. Additionally, regarding the AIC, M2 showed a lower score. Taken together, this second structure was more parsimonious and interpretable, emerging as the preferred structure for the construct.

Table 2. Model comparison between the unidimensional and the second-order models.

\begin{tabular}{cccccccc}
\hline Model & S-B $\chi^{2}$ & $d f$ & RMSEA (90\% CI) & GFI & CFI & AIC & $\Delta \chi^{2}(\Delta d f)$ \\
\hline M1 & 118.69 & 35 & $0.074(0.060,0.089)$ & 0.93 & 0.92 & 48.69 & $/$ \\
M2 & 61.48 & 33 & $0.045(0.027,0.062)$ & 0.95 & 0.97 & -4.52 & $57.21^{* * *}(2)$ \\
\hline
\end{tabular}

Note. $\mathrm{S}-\mathrm{B}_{\chi}{ }^{2}=$ Satorra-Bentler chi-square, $d f=$ degrees of freedom, RMSEA $=$ Root Mean Square Error of Approximation, GFI = Goodness of Fit Index, CFI = Comparative Fit Index, AIC = Akaike's Information Criterion, *** $p<0.001$.

In order to enact modifications representing an improvement on the final fit, the model was further inspected through the standardized residual covariance scores and standardized factor loadings, also taking into account the conceptual meaning of the items and their relevance in defining the construct. Based on these considerations, no improvements were suggested. On the one hand, the standardized residuals were small and symmetrically distributed; on the other hand, all standardized factor loadings were statistically significant at $p<0.05$, ranging from 0.54 to 0.84 for Solidarity, and from 0.65 to 0.79 for Friendship (see Figure 1).

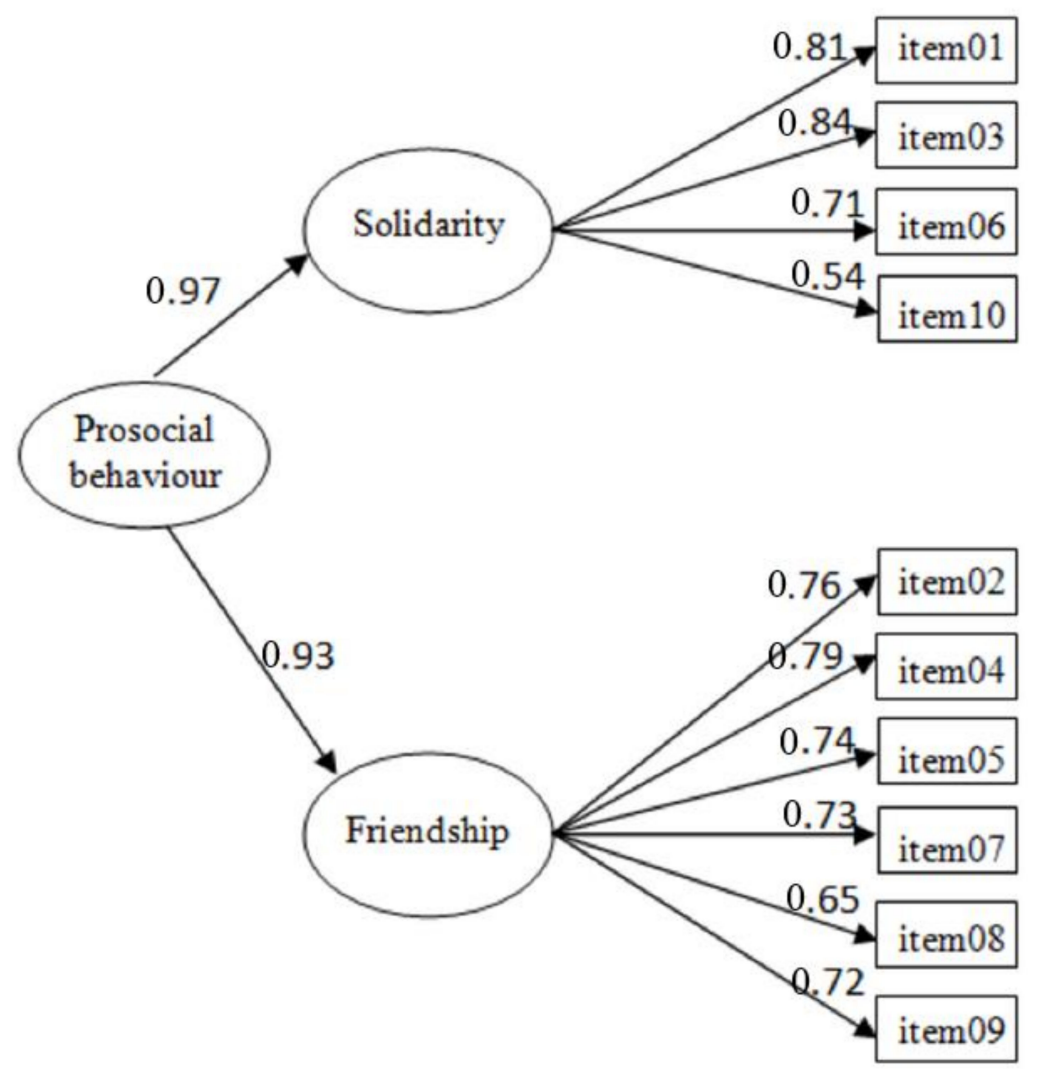

Figure 1. Final model showing the second-order factor structure for prosocial behavior $(n=478)$. 
Additional properties of the final 10-item scale were assessed with the composite reliability (CR) and Cronbach's alpha for each factor. Results showed good internal consistency for the scale as a whole ( $C R=0.92, \alpha=0.91)$, suggesting that the items were internally consistent in representing the corresponding component. Specifically, Table 3 shows the item distribution and reliability results for each underlying factor.

Table 3. Item distribution and reliability results for both components.

\begin{tabular}{|c|c|c|c|}
\hline Component & CR & $\alpha$ & Item \\
\hline Solidarity & 0.82 & 0.79 & $\begin{array}{l}\text { 01. I try to make sad people happier } \\
\text { 03. I try to help others } \\
\text { 06. I help others with their homework } \\
\text { 10. I hug my friends }\end{array}$ \\
\hline Friendship & 0.88 & 0.87 & $\begin{array}{l}\text { 02. I spend time with my friends } \\
04 \text {. I am gentle } \\
\text { 05. I share things I like with my friends } \\
\text { 07. I let others use my toys } \\
\text { 08. I like to play with others } \\
\text { 09. I trust others }\end{array}$ \\
\hline
\end{tabular}

Note. $\mathrm{CR}=$ Composite Reliability, $\alpha=$ Cronbach's alpha.

\subsection{Interaction Effects of the Interventions on Students' Prosocial Behavior}

Noteworthily, the effect of the intervention between the experimental and control groups on prosocial behavior was significant only when considering Dialogic Literary Gatherings $(F(1,200)=20.90$, $p<0.001$, Wilk's $\Lambda=0.91)$, it proving non-significant for Interactive Groups $(F(1,198)=0.07, p=0.787$, Wilk's $\Lambda=1.00$ ).

When analyzing each component, the interaction effect of Dialogic Literary Gatherings tended to be statistically significant both on Solidarity $(F(1,200)=14.98, p<0.001)$ and Friendship $(F(1,200)=21.21, p<0.001)$. This result underscored that the magnitude of the change due to the intervention was consistent across the two prosocial components. In the case of Interactive Groups, however, the component analysis yielded a non-significant effect of the intervention both on Solidarity $(F(1,198)=0.01, p=0.922)$ and on Friendship $(F(1,198)=0.10, p=0.749)$ (see Table 4$)$.

Table 4. Tests of between-subjects contrasts.

\begin{tabular}{|c|c|c|c|c|c|c|c|}
\hline Intervention & Component & Group & PreM (SD) & PostM (SD) & $F$ & $d f$ & $p$ \\
\hline Dialogic Literary Gatherings & Solidarity & $\begin{array}{c}\text { Control } \\
\text { Experimental }\end{array}$ & $\begin{array}{l}3.96(0.71) \\
3.17(1.19)\end{array}$ & $\begin{array}{l}3.94(0.73) \\
3.77(0.81)\end{array}$ & 14.98 & 1 & $<0.001$ \\
\hline & Friendship & $\begin{array}{c}\text { Control } \\
\text { Experimental }\end{array}$ & $\begin{array}{l}4.31(0.57) \\
3.50(1.24)\end{array}$ & $\begin{array}{l}4.30(0.54) \\
4.17(0.55)\end{array}$ & 21.21 & 1 & $<0.001$ \\
\hline \multirow[t]{2}{*}{ Interactive Groups } & Solidarity & $\begin{array}{c}\text { Control } \\
\text { Experimental }\end{array}$ & $\begin{array}{l}3.80(0.73) \\
3.82(0.73)\end{array}$ & $\begin{array}{l}3.80(0.64) \\
3.83(0.73)\end{array}$ & 0.01 & 1 & 0.922 \\
\hline & Friendship & $\begin{array}{c}\text { Control } \\
\text { Experimental }\end{array}$ & $\begin{array}{l}4.31(0.51) \\
4.29(0.56)\end{array}$ & $\begin{array}{l}4.25(0.44) \\
4.24(0.59)\end{array}$ & 0.10 & 1 & 0.749 \\
\hline
\end{tabular}

As can be observed in Table 4, regarding the Dialogic Literary Gatherings, scores on Solidarity increased only in the experimental group from the beginning $(M=3.17, S D=1.19)$ to the end $(M=3.77$, $S D=2.81)$ of the intervention period, whereas in the control sample the scores decreased from the starting point $(M=3.96, S D=0.71)$ to the end $(M=3.94, S D=0.73)$. Likewise, only the experimental group showed improved scores on Friendship, increasing from the beginning $(M=3.50, S D=1.24)$ to the end $(M=4.17, S D=0.55)$, with no relevant change arising in the control sample. 
Conversely, Interactive Groups exhibited no relevant change in Solidarity, with similar scores both between and within subjects; likewise, scores showed no significant change in Friendship for both student groups from the beginning to the end of the intervention.

\section{Discussion}

The goal of this study was to analyze the effect of two educational actions based on interaction and egalitarian dialogue on the development of prosocial behavior in 4th grade elementary students. To that effect, the Prosocial Behavior Scale was adapted to the Spanish language and context, confirming a bi-dimensional structure of the construct and obtaining two factors: Solidarity and Friendship. Solidarity items, on the one hand, are linked to altruism; items in Friendship are linked to trust, agreeableness, and enjoyment of time shared with friends. The results are consistent with previous studies, such as the one carried out by Caprara \& Pastorelli [33]. These aspects of prosocial behavior create a feedback loop in social situations, as students who have friends and who are socially accepted by their peers also tend to be more sociable, cooperative, prosocial, and emotionally supportive [46], and vice-versa [4]

Afterwards, the analysis carried out on the effect the two dialogue-based interventions-Dialogic Literary Gatherings and Interactive Groups had on students' prosocial behavior confirm the effectiveness of DLG for enhancing prosocial behavior, specifically on the development of the two dimensions-solidarity and friendship. Results, however, do not provide evidence that Interactive Groups generate a significant improvement in prosocial behavior. These findings are not consistent with other studies which have shown that IG improve social cohesion [25]. Hence, a detailed discussion about the specific characteristics of each intervention would shed light on these inconsistencies.

\subsection{Specific Features of the Two Dialogic-Based Interventions}

Whereas dialogue and interaction are a cornerstone of both interventions, the particular patterns in which students and teachers put talk into work differ, considerably, from one to another. In the case of DLG, children engage in a collective interpretation of the great literary works, where dialogue is not prompted by an adult and starts from their own meanings and reflections about their reading. Consistent with previous studies [29,32], children provide articulated contributions that elicit high-level thinking and reasoning about friendship, help, justice, or discrimination. This dialogic dynamic creates affordances for children to engage in a collective reasoning about human relationships where prosocial behavior takes place, which has an important role in building relationships across the lifespan [47]. Instead, students' interactions in IG are focused on curricular tasks where mathematical and academic talk prevails.

Although IG seek to foster peer support when solving academic activities, there is no specific time and space to reflect on this fact. Consequently, some students might not fully internalize the benefits of actions such as helping, sharing, cooperating in which they are involved during IG.

On the other hand, organizational features of the intervention might be another factor that influenced the differences in prosocial development in our study. Whereas DLG takes place in a whole classroom setting that allows for all students to reflect together around $50 \mathrm{~min}$, in IG students are organized in small groups working in different short activities $15 \mathrm{~min}$ each. Thus, time management in IG might limit the opportunities to reflect about peer support in the learning process. Additionally, the fundamental goal of this dynamic is to boost students' learning, and consequently their academic achievement, while receiving peer support. Therefore, mutual help and support play a crucial role in this type of small-group classroom structures. However, the main focus of the volunteer-facilitated groups in our study has been to promote children's learning and thinking to solve mathematical tasks. The less opportunities to talk about and reflect on help and support, or other prosocial-related topics, may explain why no significant result has been reported in the students involved in IG.

The role of the teacher in both interventions presents differences that may affect the results as well. The teacher is the facilitator who takes turns encouraging everybody to contribute to the discussion 
in DLG. By contrast, in the IG the teacher plans the activities to be carried out in the small groups, whereas the interactions in each group are facilitated by different volunteers. These individual differences, which has not been controlled in our study, might impact group success. Research conducted by Webb and colleagues [48] about the role of facilitators in promoting effective group collaboration showed that the quality of the interaction in the groups depends on each teacher's instructional practices [48].

\subsection{Methodological Aspects}

Some aspects in the research design may have also affected the non-significant results in the case of IG. The fact that the intervention spanned only 10 sessions seems to be rather limited, in the case of IG, to achieve measurable changes in prosocial behavior, but not necessarily in DLG, where a significant effect was achieved. Related to the specific features of the dialogue pointed out before, we must acknowledge children have less opportunities to reflect on their behaviors and attitudes towards other in IG than in DLG. Anyhow, studies such as the one led by Sin and Lyubomirsky [49] showed that longer interventions bear more beneficial results in well-being and other aspects: when the activity is maintained over a longer period of time, participants have the opportunity to transform activities into daily habits. Therefore, a long-lasting intervention in IG could lead to significative changes not only in mathematical performance [26] but also in prosocial behavior.

\section{Conclusions}

This study is an important step towards contributing scientific knowledge to support the evidence it is possible to promote prosocial behavior by creating a prosocial classroom environment [50], but also it can contribute to create "effective learning environments", as a mean to achieve the Sustainable Development Goal 4: "Ensure inclusive and equitable quality education and promote lifelong learning opportunities for all' [3]. Creating dialogic learning environments that foster prosocial development provides a powerful resource for teachers to build safe and supportive educational contexts in which no child is left behind.

As demonstrated by this study and consistently with previous research, neither all forms of classroom structure nor all types of dialogue are equally effective for learning [17,29] and prosocial behaviour [4]. Specifically, in IG, even though peer support is fostered the children's discourse mainly focuses in mathematics tasks leaving limited opportunities to reflect on the importance of helping, sharing and cooperating $[25,26]$. Promoting children's dialogues about prosocial behavior in IG would increase their metacognitive knowledge about its benefits for learning and well-being [51]. Therefore, metacognitive awareness is developed through children's dialogues when they think and reflect on their behavior. This might equip the children with tools for acting prosocially and ultimately promoting a classroom climate of peace and non-violence in multicultural societies, as a relevant contribution for a sustainable development.

\section{Limitation and Further Research}

Limitations in this study should be acknowledged. Firstly, students were not randomly assigned to the experimental and control groups; the groups, however, were very similar in composition. Secondly, data gathered on prosocial behavior was entirely self-reported; other techniques could be used to gather data on this variable, such as observation or peer assessment. Despite these limitations, this study provides scientific evidence of the importance of collective reflection, interaction, and dialogue around social values, as reported in the DLG condition, for the development of prosocial behavior, and, consequently, for the improvement of healthy relationships in safe and supportive schools.

The egalitarian dialogue is a plausible explanation for the impact of DLG, but this has not directly tested by this study. Further research is needed to clarify whether the positive effect of DLG in students' prosocial behavior is influenced by variables such as egalitarian dialogue, the choice of books, the teacher scaffolding or by the interactions among them. 
Similarly, open questions remain to be explored with regards to IG as a potential learning environment for prosocial development. There is a need to conduct extensive research to elucidate whether engaging students in dialogues about peer support in the learning process promote prosocial behavior in students, especially in the Solidarity dimension. Moreover, one promising research question to tackle is whether volunteers' individual differences affect socioemotional development and learning of the students. Increasing efforts to advance knowledge on these challenges would contribute to achieve an inclusive and equitable education for all.

Author Contributions: Conceptualization, L.V.-G., R.G.-C. and A.E. Formal analysis, L.Y.-M. Funding acquisition, R.G.-C. Methodology, L.V.-G., R.G.-C. and L.Y.-M. Writing-original draft, L.V.-G. and A.E. Writing-review \& editing, R.G.-C.

Funding: This research was funded by Spanish Government National Programme for Research Aimed at the Challenges of Society, grant number: EDU2015-66395-R (MINECO/FEDER, UE).

Conflicts of Interest: The authors declare no conflict of interest.

\section{References}

1. Neaman, A.; Otto, S.; Vinokur, E. Toward an integrated approach to environmental and prosocial education. Sustainability 2018, 10, 583. [CrossRef]

2. European Commission. Europe 2020. A European Strategy for Smart, Sustainable and Inclusive Growth. COM 2010-2020; European Commission: Brussels, Belgium, 2010.

3. UNESCO Education for Sustainable Development (ESD). Available online: http://www.unesco.org/ new/en/education/themes/leading-the-international-agenda/education-for-sustainable-development/ (accessed on 12 June 2018).

4. Wentzel, K. Prosocial behaviour and schooling. Prosoc. Behav. 2015, 5, 57-61.

5. Eisenberg, N.; Spinrad, T.L.; Knafo-Noam, A. Prosocial development. In Handbook of Child Psychology, 7th ed.; Lamb, M.E., Garcia Coll, C., Lerner, R.M., Eds.; Wiley: New York, NY, USA, 2015; Volume 3, pp. 610-658.

6. Batson, C.D. Altruism in Humans; Oxford University Press: Oxford, MS, USA, 2011.

7. Berger, C.; Palacios, D. Associations between prosocial behavior, machiavellianism, and social status: Effects of per norms and classroom social contexts. JOLLAS 2014, 6, 19-30. [CrossRef]

8. Padilla-Walker, L.; Fraser, A.M.; Black, B.; Bean, R. Associations between friendship, sympathy, and prosocial behavior toward friends. J. Res. Adolesc. 2014, 25, 28-35. [CrossRef]

9. Véronneau, M.H.; Vitaro, F.; Brendgen, M.; Dishion, T.J.; Tremblay, R.E. Transactional analysis of the reciprocal links between peer experiences and academic achievement from middle childhood to early adolescence. Dev. Psychol. 2010, 46, 773. [CrossRef] [PubMed]

10. Weinstein, N.; Ryan, R.M. When helping helps: Autonomous motivation for prosocial behavior and its influence on well-being for the helper and recipient. J. Pers. Soc. Psychol. 2010, 98, 222. [CrossRef] [PubMed]

11. Caprara, G.V.; Barbaranelli, C.; Pastorelli, C.; Bandura, A.; Zimbardo, P. Prosocial foundations of children's academic achievement. Psychol. Sci. 2000, 11, 302-306. [CrossRef] [PubMed]

12. Chaparro, M.P.; Grusec, J.E. Neuroticism moderates the relation between parenting and empathy and between empathy and prosocial behavior. Merrill Palmer Q. 2016, 62, 105-128. [CrossRef]

13. Björkqvist, K.; Österman, K.; Kaukiainen, A. Social intelligence - empathy = aggression? Aggress. Violent Behav. 2000, 5, 191-200. [CrossRef]

14. Olweus, D. Bullying at School: What We Know and What We Can Do; Blackwell Publishing: Hoboken, NJ, USA, 1993.

15. Bernstein, D.P.; Cohen, P.; Skodol, A.; Bezirganian, S.; Brook, J.S. Childhood antecedents of adolescent personality disorders. Am. J. Geriatr. Psychiatry 1996, 153, 907.

16. Ohl, M.; Fox, P.; Mitchell, K. Strengthening socio-emotional competencies in a school setting: Data from the Pyramid project. Br. J. Educ. Psychol. 2013, 83, 452-466. [CrossRef] [PubMed]

17. Howe, C.; Abedin, M. Classroom dialogue: A systematic review across four decades of research. Camb. J. Educ. 2013, 43, 325. [CrossRef]

18. Resnick, L.B.; Asterhan, C.S.; Clarke, S.N. Socializing Intelligence through Academic Talk and Dialogue; AERA: Washington, DC, USA, 2015.

19. Gillies, R.M. Dialogic interactions in the cooperative classroom. Int. J. Educ. Res. 2016, 76, 178-189. [CrossRef] 
20. Kershner, R. Including psychology in inclusive pedagogy: Enriching the dialogue? IJEP 2016, 5, 112-139. [CrossRef]

21. Kutnick, P.; Brighi, A.; Colwell, J. Interactive and socially inclusive pedagogy: A comparison of practitioner and child-oriented cognitive/learning activities involving four year old children in preschools in England. EECERJ 2016, 24, 265-286. [CrossRef]

22. García-Carrión, R.; Molina-Luque, F.; Roldán, S.M. How do vulnerable youth complete secondary education? The key role of families and the community. J. Youth Stud. 2018, 21, 701-716. [CrossRef]

23. Garcia Yeste, C.; Gairal Casado, R.; Munté Pascual, A.; Plaja Viñas, T. Dialogic literary gatherings and out-of-home child care: Creation of new meanings through classic literature. Child Fam. Soc. Work 2017. [CrossRef]

24. Valero, D.; Redondo-Sama, G.; Elboj, C. Interactive groups for immigrant students: A factor for success in the path of immigrant students. Int. J. Incl. Educ. 2017. [CrossRef]

25. Valls, R.; Kyriakides, L. The power of Interactive Groups: How diversity of adults volunteering in classroom groups can promote inclusion and success for children of vulnerable minority ethnic populations. Camb. J. Educ. 2013, 43, 17-33. [CrossRef]

26. García-Carrión, R.; Díez-Palomar, J. Learning communities: Pathways for educational success and social transformation through interactive groups in mathematics. EERJ 2015, 14, 151-166. [CrossRef]

27. Aubert, A.; Molina, S.; Schubert, T.; Vidu, A. Learning and inclusivity via Interactive Groups in early childhood education and care in the Hope school, Spain. Learn. Cult. Soc. Interact. 2017, 13, 90-103. [CrossRef]

28. Elboj, C.; Niemelä, R. Sub-communities of mutual learners in the classroom: The case of Interactive groups. Rev. Psicodidáct. 2010, 15, 177-189.

29. Hargreaves, L.; García-Carrión, R. Toppling teacher domination of primary classroom talk through dialogic literary gatherings in England. FORUM 2016, 58, 15-25. [CrossRef]

30. Alvarez, P.; García-Carrión, R.; Puigvert, L.; Pulido, C.; Schubert, T. Beyond the walls: The social reintegration of prisoners through the dialogic reading of classic universal literature in prison. Int. J. Offender Ther. Comp. Criminol. 2018, 62, 1043-1061. [CrossRef] [PubMed]

31. Reznitskaya, A.; Gregory, M. Student thought and classroom language: Examining the mechanisms of change in dialogic teaching. Educ. Psychol. 2013, 48, 114-133. [CrossRef]

32. García-Carrión, R. What the dialogic literary gatherings did for me: The personal narrative of an 11-Year-old boy in a rural community in England. Qual. Inq. 2015, 21, 913-919. [CrossRef]

33. Caprara, G.V.; Alcini, P.; Mazzotti, E.; Pastorelli, C. Sviluppo e caratteristiche di tre scale per la misura dell'aggressivita'fisica e verbale, del comportamento prosociale. In Indicatori e Precursori Della Condotta Aggressiva; Caprara, G.V., Laeng, M., Eds.; Bulzoni: Roma, Italy, 1988; pp. 121-144. (In Italian)

34. Caprara, G.V.; Pastorelli, C. Early emotional instability, prosocial behaviour, and aggression: Some methodological aspects. Eur. J. Pers. 1993, 7, 19-36. [CrossRef]

35. European Commission. Ethics for Researchers. Facilitating Research Excellence in FP7; European Commission: Brussels, Belgium, 2013.

36. Tabachnick, B.G.; Fidell, L.S. Using Multivariate Statistics, 5th ed.; Allyn \& Bacon: Boston, MA, USA, 2007.

37. Brown, T. Confirmatory Factor Analysis for Applied Research; Guildford: New York, NY, USA, 2006.

38. Lei, M.; Lomax, R.G. The effect of varying degrees of nonnormality in structural equation modeling. Struct. Equ. Model. 2005, 12, 1-27. [CrossRef]

39. Bentler, P.M. EQS Structural Equations Program Manual; Multivariate Software, Inc.: Encino, CA, USA, 2005.

40. Ullman, J.B. Structural equation modeling. In Using Multivariate Statistics, 5th ed.; Tabachnick, B.G., Fidell, L.S., Eds.; Allyn \& Bacon: Boston, MA, USA, 2006; pp. 653-771.

41. Hair, J.F.; Black, W.C.; Babin, B.J.; Anderson, R.E. Multivariate Data Analysis, 7th ed.; Pearson Prentice Hall: Upper Saddle River, NJ, USA, 2010.

42. Hu, L.T.; Bentler, P.M. Cutoff criteria for fit indices in covariance structure analysis: Conventional criteria versus new alternatives. Struct. Equ. Model. 1999, 6, 1-55. [CrossRef]

43. Hoyle, R.H.; Panter, A.T. Writing about structural equation models in structural equation modeling. In Structural Equation Modeling: Concepts. Issues and Applications; Hoyle, R.H., Ed.; Sage Publications Inc.: Thousand Oaks, CA, USA; pp. 158-176.

44. Fornell, C.; Larcker, D.F. Evaluating structural equation models with unobservable variables and measurement error. J. Mark. Res. 1981, 18, 39-50. [CrossRef]

45. Nunnally, J.C. Psychometric Theory, 2nd ed.; McGraw-Hill: New York, NY, USA, 1978. 
46. Newcomb, A.F.; Bagwell, C.L. Children's friendship relations: A meta-analytic review. Psychol. Bull. 1995, 117, 306-347. [CrossRef]

47. Brownell, C.A. Prosocial behavior in infancy: The role of socialization. Child Dev. Perspect. 2016, 10, $222-227$. [CrossRef]

48. Webb, N.M.; Franke, M.L.; De, T.; Chan, A.G.; Freund, D.; Shein, P.; Melkonian, D.K. “Explain to your partner": Teachers' instructional practices and students' dialogue in small groups. Camb. J. Educ. 2009, 39, 49-70. [CrossRef]

49. Sin, N.L.; Lyubomirsky, S. Enhancing well-being and alleviating depressive symptoms with positive psychology interventions: A practice-friendly meta-analysis. J. Clin. Psychol. 2009, 65, 467-487. [CrossRef] [PubMed]

50. Schonert-Reichl, K.A.; O'Brien, M.U. Social and emotional learning and prosocial education. In Handbook of Prosocial Education; Brown, P.M., Corrigan, M.W., Higgins-D’Alessandro, A., Eds.; Rowman \& Littlefield: Lanham, MD, USA; pp. 311-345.

51. Mercer, N.; Howe, C. Explaining the dialogic processes of teaching and learning: The value and potential of sociocultural theory. Learn. Cult. Soc. Interact. 2012, 1, 12-21. [CrossRef]

(C) 2018 by the authors. Licensee MDPI, Basel, Switzerland. This article is an open access article distributed under the terms and conditions of the Creative Commons Attribution (CC BY) license (http:/ / creativecommons.org/licenses/by/4.0/). 